\title{
Expanding the armamentarium for reoperative coronary artery bypass grafting
}

\author{
Maria Currie ${ }^{1}$ \\ ${ }^{1}$ Stanford Medicine
}

July 31, 2021

Expanding the armamentarium for reoperative coronary artery bypass grafting

Short title : Expanding the armamentarium for redo CABG

Maria Currie, MD $\mathrm{PhD}^{1}$

${ }^{1}$ Department of Cardiothoracic Surgery, Stanford University School of Medicine

\section{Disclosure}

The author has no conflicts of interest to disclose.

\section{Funding}

None.

\section{Address for Correspondence:}

Maria Currie, MD PhD

Clinical Assistant Professor

Department of Cardiothoracic Surgery

Stanford University School of Medicine

Center for Academic Medicine

453 Quarry Road, Room 267

MC 5661

Stanford, CA 94305

E-mail: mecurrie@stanford.edu

\section{Keywords}

Gastroepiploic artery; Redo coronary artery bypass grafting

Reoperative coronary artery bypass grafting (CABG) is associated with increased patient mortality and morbidity as compared to primary coronary revascularization. ${ }^{1-5}$ This increased risk is due not only to the potential for increased patient comorbidities, but also to the risk of injury to cardiovascular structures on re-entry and mediastinal dissection. ${ }^{1-5}$ Potential pitfalls during re-entry and mediastinal dissection in reoperative CABG include injury to internal thoracic artery or vein grafts, native coronary vessels, the right ventricle, or the innominate vein. ${ }^{1}$ Therefore, a meticulous image-guided and multidisciplinary team-based 
approach for preoperative assessment of reoperative cardiac surgery has been proposed. ${ }^{6}$ Furthermore, novel techniques are required in patients undergoing reoperative CABG with limited bypass conduit options.

In this issue of the Journal, Shiraishi et al. document the outcomes of reoperative CABG using the right gastroepiploic artery (RGEA) through a left anterolateral thoracotomy at a single cardiac center. ${ }^{7}$ The goals of the study are to specifically examine perioperative morbidity and mortality and to assess the impact of reoperative CABG with RGEA grafting through a left anterolateral thoracotomy by evaluating cardiac functional values between pre- and postoperative status. This is a retrospective cohort study examining the outcome of eleven patients from a single institution that underwent reoperative CABG with RGEA and RGEA-saphenous vein composite grafts through a left anterolateral thoracotomy and midline epigastric approach. Ten of these patients underwent off-pump CABG. Bypass target vessels of both RGEA and RGEA-saphenous vein composite grafts included the left anterior descending, diagonal, circumflex, and right coronary arteries. All grafts were patent on angiogram or coronary computed tomography at postoperative day seven. No in-hospital deaths were observed. Postoperatively, improvements were observed in left ventricular end-diastolic volume, left ventricular end-systolic volume, and left ventricular ejection fraction. From these findings, the authors concluded that in select patients, off-pump reoperative CABG with RGEA grafting through a left anterolateral thoracotomy is a safe and effective surgical procedure.

Shiraishi et al. present an interesting and topical premise. Historically, the RGEA was first proposed for indirect myocardial revascularization in the 1960 's. ${ }^{8}$ In 1987, Pym et al. first described direct revascularization of the right coronary artery and obtuse marginal branches using RGEA grafts. ${ }^{9}$ That same year, Suma et al. described the use of RGEA for reoperative coronary revascularization of the left anterior descending artery through a transdiaphragmatic approach in two patients. ${ }^{10}$ The transdiaphragmatic approach facilitates avoidance of both full sternotomy and cardiopulmonary bypass. ${ }^{7}$ Since that time, others have described off pump reoperative CABG using the RGEA, primarily to the right coronary artery circulation. $11,12,13,14,15$ Nevertheless, the RGEA is an infrequently used bypass conduit.

As Shiraishi and colleagues concede, RGEA use should be limited to select appropriate bypass candidates. ${ }^{7}$ This judicious patient selection is reflected in their small cohort size. Similar to radial artery bypass grafts, RGEA graft patency rate is highly dependent on the degree of stenosis of the native target vessel. ${ }^{16,17}$ When used to bypass native vessels with greater than $90 \%$ stenosis, RGEA patency rates were reported as $94.7 \%$ and $90.2 \%$ at 5 and 8 years after surgery, respectively. ${ }^{18}$ Therefore, the RGEA has good patency when bypassing critically stenosed or occluded native coronary arteries; however, native coronary competitive flow may lead to RGEA bypass spasm and occlusion. Its small caliber and predisposition to vasospasm have limited widespread RGEA use as a bypass graft. ${ }^{13,19}$

Despite these limitations, there has been more recent interest in RGEA grafts for full arterial revascularization. Within the last year, Kim and colleagues have shown comparable results between the ten year patency rates of both RGEA and right internal thoracic artery composite grafts. ${ }^{20}$ Furthermore, Yamamoto et al. recently published patency rates for free gastroepiploic artery (GEA) bypass grafts. ${ }^{21}$ The early patency rate of free GEA grafts was $98.6 \%$. The long-term patency rates of the free GEA grafts were $96.5 \%, 95 \%$, and $86.6 \%$ at 5,10 , and 15 years, respectively. ${ }^{21}$

As cardiac surgeons, we face an increasing number of complex patient presentations, including reoperations. Knowledge of a broad range of bypass conduit options will surely strengthen our armamentarium for reoperative CABG when there may be limited conduit availability. I commend Shiraishi and colleagues for their surgical ingenuity and mastery.

\section{REFERENCES}

1. Roselli EE, Pettersson GB, Blackstone EH, et al. Adverse events during reoperative cardiac surgery: frequency, characterization, and rescue. The Journal of thoracic and cardiovascular surgery. $J$ Thorac Cardiovasc Surg. 2008;135:316-323.

2. Yap CH, Sposato L, Akowuah E, et al. Contemporary results show repeat coronary artery bypass grafting remains a risk factor for operative mortality. Ann Thorac Surg. 2009; 87 : 1386- 1391. 
3. Launcelott S, Ouzounian M, Buth KJ, Légaré JF. Predicting in-hospital mortality after redo cardiac operations: development of a preoperative scorecard. Ann Thorac Surg. 2012;94:778-784.

4. Maltais S, Widmer RJ, Bell MR, et al. Reoperation for coronary artery bypass grafting surgery: outcomes and considerations for expanding interventional procedures. Ann Thorac Surg . 2017;103:18861892.

5. Bianco V, Kilic A, Gleason TG, et al. Reoperative cardiac surgery is a risk factor for long-term mortality. Ann Thorac Surg . 2020;110:1235-1242.

6. Kindzelski BA, Bakaeen FG, Tong MZ, et al. Modern practice and outcomes of reoperative cardiac surgery. J Thorac Cardiovasc Surg . 2021;1-12.

7. Shiraishi M, Kimura N, Yamaguchi A. Early Cardiac Contractility Outcome of Reoperative Coronary Artery Bypass Grafting Using Right Gastroepiploic Artery. J Card Surg. 2021. In press.

8. Bailey CP, Hirose T, Aventura A, et al: Revascularization of the ischemic posterior myocardium. Diseases of the Chest.1967;52:273-285.

9. Pym J, Brown PM, Charrette EJP, et al: Gastroepiploic coronary anastomosis. A viable alternative bypass graft. J Thorac Cardiovasc Surg . 1987; 94:256-259.

10. Suma H, Fukumoto H, Takeuchi A. Coronary artery bypass grafting by utilizing in situ right gastroepiploic artery. Basic study and clinical application. Ann Thorac Surg . 1987;44:394-397.

11. Grandjean JG, Mariani MA, Ebels T. Coronary reoperation via small laparotomy using right gastroepiploic artery without cardiopulmonary bypass. Ann Thorac Surg . 1996;61:1853-1855.

12. Akhter M, Lajos TZ, Grosner G, Bergsland J, Salerno TA. Reoperations with the right gastroepiploic artery without cardiopulmonary bypass. J Card Surg . 1997;12:210-214.

13. Taggart DP. Radial Artery-Gastroepiploic Artery Composite Graft for Redo CABG. Ann Thorac Surg . 1997;64:1473-1475.

14. Tavilla G, Pijls NHJ. Right gastroepiploic artery for coronary bypass reoperation without cardiopulmonary bypass. J Cardiovasc Surg . 1997;38:77-80.

15. Glineur D, Noirhomme P, Poncelet A, et al. Gastroepiploic artery minimally invasive grafting in reoperative patients with patent mammaries. Ann Thorac Surg . 2005;79:1606-1609.

16. Voutilainen S, Verkkala K, Jarvinen A, et al. Angiographic 5-year follow-up study of right gastroepiploic artery grafts. Ann Thorac Surg . 1996; 62:501-505.

17. Suma H. Optimal use of the gastroepiploic artery. Semin Thorac Cardiovasc Surg. 1996; 8: 24-28.

18. Suzuki T, Asai T, Nota H, et al. Early and long-term patency of in situ skeletonized gastroepiploic artery after off-pump coronary artery bypass graft surgery. Ann Thorac Surg . 2013;96:90-5.

19. Glineur D, Hanet C. Competitive flow in coronary bypass surgery: is it a problem? Curr Opin Cardiol. 2012; 27: 620-628.

20. Kim MS, Hwang HY, Cho KR, Kim KB. Right gastroepiploic artery versus right internal thoracic artery composite grafts: 10-year patency and long-term outcomes. J Thorac Cardiovasc Surg. 2020; $1-11$.

21. Yamamoto T, Mutsuga M, Matsuura A, et al. Long-term outcome 10 years after free gastroepiploic artery graft for coronary artery bypass surgery. Ann Thorac Surg. 2020. In press. 